\title{
Molten Steel Level Control of Strip Casting Process Monitoring by Using Self-Learning Fuzzy Controller
}

\author{
Hung-Yi Chen ${ }^{1}$ and Shiuh-Jer Huang ${ }^{2}$ \\ ${ }^{1}$ Ming Chi University of Technology, \\ ${ }^{2}$ National Taiwan University of Science and Technology \\ Taiwan, R.O.C.
}

\section{Introduction}

The twin-roll strip casting process is a typical steel-strip production method which combines continuous casting and hot rolling process. The production line from molten liquid steel to the final steel-strip is shortened and the production cost is reduced significantly compared to the conventional continuous casting. The twin-roll strip casting process can produce 1-5 $\mathrm{mm}$ thin steel strip directly from the molten steel. Furthermore, since the strip casting process has high cooling rate, it can improve the mechanical properties of steel (Liang et al. 1997; Cook et al. 1995). Usually, the molten steel level is controlled at a preset desired level to monitor the normal strip casting operation. During the roll casting process, once the molten metal contacts with the rotating rolls, a thin solidification shell is formed on the surface of each roll. The shell thickness gradually grows from each roll surface, finally contacts with each other and weld together at a position around the roll exit, called the solidification final point. If the molten metal level is higher than the specified value, the solidification final point will occur at a point above the roll exit. That will result in heat cracking and damage to the cooling roll surface in addition to material structural abnormalities of the steel strip. If the molten metal level is lower than the desirable value, the solidification final point will occur at a point below the roll exit. The steel strip surface will have inferior quality due to the breakout and oxidation. Hence, the molten metal level is an important process control parameter to guarantee the solidification final point and rolling strip quality. The molten steel level must maintain within a specific range during the full casting process except the initial startup operating mode by filling the molten steel into the twin roll cylinders from the tundish.

Since the strip casting process has nonlinear dynamics uncertainty and coupled behaviors, accurate molten steel level control problem is still an important research topic to guarantee the steel strip quality. Graebe et al. (1995) verified the dynamic model and various nonlinearities appearing in the continuous casting process and proposed different issues that had to be solved in controller design. Hesketh et al. (1993) applied an adaptive control strategy for the mold level control of a continuous steel slab casting. Hong et al. (2001) investigated the modeling and control problem of a twin-roll strip caster. They analyzed different critical dynamics, including molten steel pool leveling, and developed a two-level 
control strategy to achieve a constant strip thickness and maintain a constant roll separating force.

Since the dynamic characteristic of this strip casting process is very complicated, it is difficult to establish an appropriate dynamic model for a model-based controller design. Hence, a model-free fuzzy control strategy is considered to solve this problem (Dussud et al. 1998; Joo et al. 2002; Park and Cho 2005). However, the design of a traditional fuzzy controller fully depends on an expert, or the experience of an operator, to establish the fuzzy rule bank. Generally, this knowledge is difficult to obtain. A time consuming adjusting process is required to achieve the specified control performance. These factors hinder its application and implementation.

Herein, a self-learning fuzzy controller with learning ability is utilized without the process dynamic model requirement to control the molten steel level of strip casting process. This control strategy can establish the fuzzy control rule tables automatically from zero initial rules and adjust on line to tackle the system variation and disturbance for reducing the effort of trial-and-error process. Here, the self-learning fuzzy controller is designed for regulating the height of the stopper controlled by an electric servomotor to achieve the desired molten steel level during the strip casting process. The control performance of the designed controller is evaluated based on numerical simulation results. For approaching a real case implementation, the simulation cases are selected based on the semi-experimental system dynamic model and parameters (Joo et al. 2002). In addition, the performance of this intelligent controller is compared with that of a traditional PID technique to show the performance improvement.

This article is organized as follows: Section 2 describes the twin-roll strip casting process dynamics and system model for simulation purpose. Section 3 presents the model-free selflearning fuzzy control strategy. Section 4 describes the numerical results of this intelligent controller. Final conclusions are presented in Section 5.

\section{Process dynamics and system model for simulation purposes}

A process mathematical model, which describes the relationship between the command inputs and the measured outputs, is required for the numerical simulation to evaluate the dynamic performance of a model-free controller. The mathematical model for the molten steel leveling dynamics developed in (Joo et al. 2002) is adopted and described in this section. Fig. 1 shows a schematic drawing of a twin-roll strip casting process. For developing the mathematical model, it is assumed that the molten steel is incompressible and two rolls are identical. The continuity equation of the liquid steel can be described as:

$$
\frac{\mathrm{dV}}{\mathrm{dt}}=\mathrm{Q}_{\mathrm{in}}-\mathrm{Q}_{\mathrm{out}}
$$

where $\mathrm{V}$ is the volume of the molten steel stored between the twin-roll cylinders, $\mathrm{Q}_{\text {in }}$ is the input flow rate into the space between roll cylinders and $Q_{\text {out }}$ is the output flow rate from the roll cylinders. The volume $\mathrm{V}$ can be calculated as:

$$
\mathrm{V}=\mathrm{AL}_{\mathrm{r}}
$$

where $L_{r}$ is the length of the roll cylinders and $A$ is the oblique area shown in Fig. 1. 


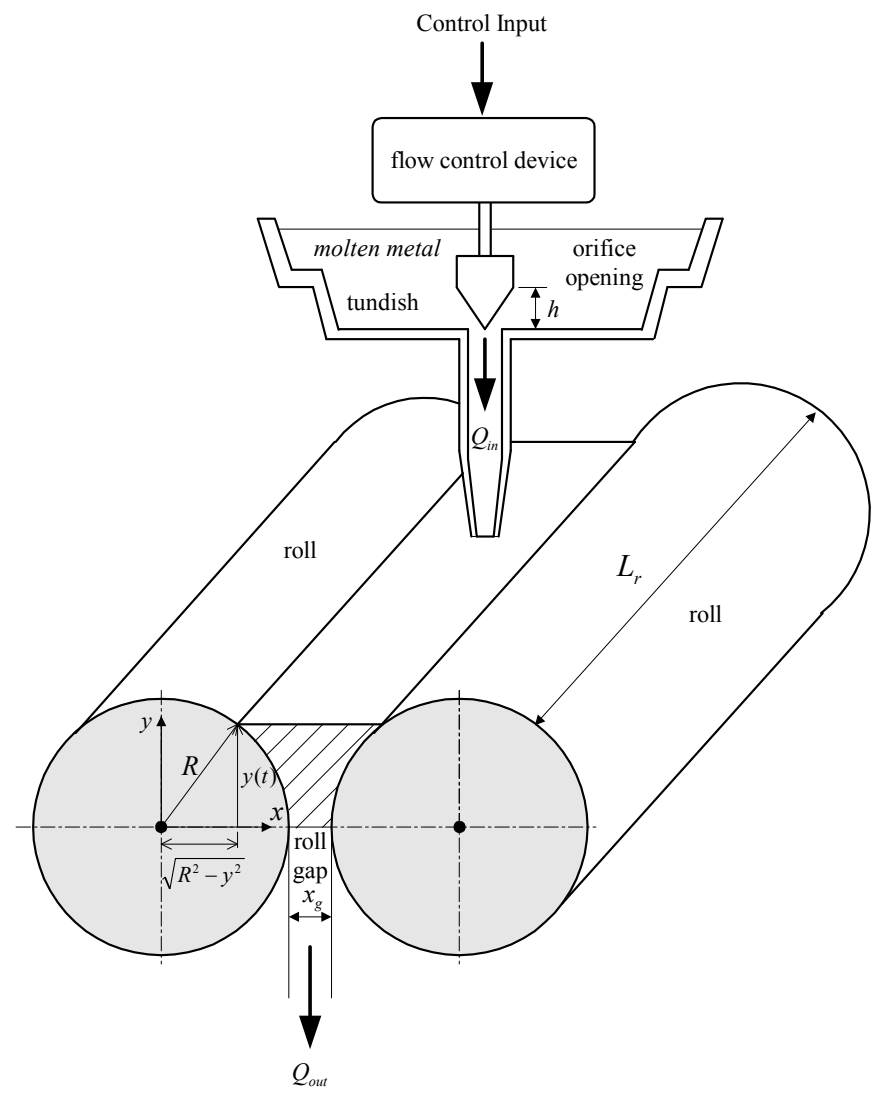

Fig. 1. Schematic diagram of the twin-roll strip casting process

$$
A=2 \int_{0}^{y}\left[\frac{x_{g}(t)}{2}+R-\sqrt{R^{2}-y^{2}}\right] d y
$$

where $x_{g}(t)$ is the roll gap, $R$ is the radius of the roll cylinder and $y(t)$ is the height of molten metal above the axis of rollers. By substituting equations (2) and (3) into equation (1), obtain:

$$
\frac{d V}{d t}=L_{r} \frac{d A}{d t}=L_{r}\left[y \frac{d x_{g}}{d t}+\left(x_{g}+2 R-2 \sqrt{R^{2}-y^{2}}\right) \frac{d y}{d t}\right]
$$

If $\left(x_{g}+2 R-2 \sqrt{R^{2}-y^{2}}\right)$ is defined as $B_{r}\left(x_{g}, y\right)$, the following form can be derived from equation (1).

$$
\frac{d y}{d t}=\frac{1}{B_{r}\left(x_{g}, y\right) L_{r}}\left(Q_{i n}-Q_{o u t}-L_{r} y \frac{d x_{g}}{d t}\right)
$$


Here, the input flow rate $Q_{i n}$ can be derived from the stopper opening height $h(t)$ and a nonlinear time varying input flow rate parameters $a(t)$ depends on the shape of the nozzle and the stopper, clogging/unclogging dynamics and the height and the viscosity of the molten metal in the tundish.

$$
\mathrm{Q}_{\text {in }}=\mathrm{a}(\mathrm{t}) \cdot \mathrm{h}(\mathrm{t})
$$

where the orifice opening, $\mathrm{h}(\mathrm{t})$, equal to the height of the stopper is controlled by an electric servomotor. Due to fast response of the electric servomotor, the stopper motion dynamics is assumed to be negligible. In addition, if the response of the stopper actuator is fast enough, the orifice opening can be derived as:

$$
h(t)=k u(t)
$$

where $u(t)$ denotes the control input and $k$ is the servo gain.

The output flow rate $Q_{\text {out }}$ can be derived from the product of roll surface tangential velocity $\mathrm{v}_{\mathrm{r}}$, roll gap $\mathrm{x}_{\mathrm{g}}$ and the length of the roll cylinder $\mathrm{L}_{\mathrm{r}}$.

$$
\mathrm{Q}_{\text {out }}=\mathrm{L}_{\mathrm{r}} \mathrm{x}_{\mathrm{g}} \mathrm{v}_{\mathrm{r}}
$$

The dynamic model will only be used in the numerical simulations for evaluating the dynamic performance of the model-free self-learning fuzzy controller. The designing process of this intelligent controller does not need this dynamic model.

\section{Self-learning fuzzy control strategy}

Generally, for a non-linear dynamic system with uncertainties, it is very difficult to establish an accurate mathematical model for designing the control laws. Although the linearized model or simplified model can be employed to design the controller, the control performance of these model-based controllers still depends on many factors, such as the working position and operating conditions. Hence, model-free fuzzy control strategy was proposed to solve this kind of problem. It does not need a mathematical model for designing a fuzzy logic control law. In addition, a fuzzy logic controller can compensate the environmental variation during operation processes. However, to establish the fuzzy rule tables of a traditional fuzzy controller still depends on an expert or the experience of an operator. Generally, this knowledge is not easy to obtain and a time-consuming adjusting process is required to achieve the specified control performance.

A self-learning fuzzy controller with learning ability was utilized to establish the fuzzy rule tables on-line automatically for reducing the effort of trial-and-error process (Chen and Huang 2004). It facilitates the design process of a fuzzy controller and makes the implementation of a fuzzy controller easier. Usually, the output response error and the change of error are selected as the fuzzy input variables. Both of them stimulate two fuzzy subsets (E and CE) for each sampling instant. Then, maximum four fuzzy rules in the fuzzy rule table are fired instead of the entire rule table and only these four rules are modified in each sampling time. This method can significantly reduce the computing time, therefore increasing the sampling frequency. Since this approach has learning ability to establish and regulate the fuzzy rule tables continuously, its control implementation can begin with zero 
initial fuzzy rules. The fuzzy rules were adjusted on-line by means of a simple modification equation for each rule instead of a performance decision table.

Fig. 2 shows that the self-learning part is added into a traditional fuzzy controller to form a self-learning fuzzy controller. Among them, the traditional fuzzy controller carries out the mission of control and the self-learning part is responsible for real-time recognition of the system variation. The self-learning part contains three steps: performance measure, model estimation and rule modification. The system performance measure is to calculate the deviation between the system output and the specified values. The purpose of system performance measure is to establish a successful correcting basis for a learning controller. Usually, two physical features including system output error and the change of error are chosen as performance indices to establish a performance decision table, which is similar to establish a fuzzy rule table.

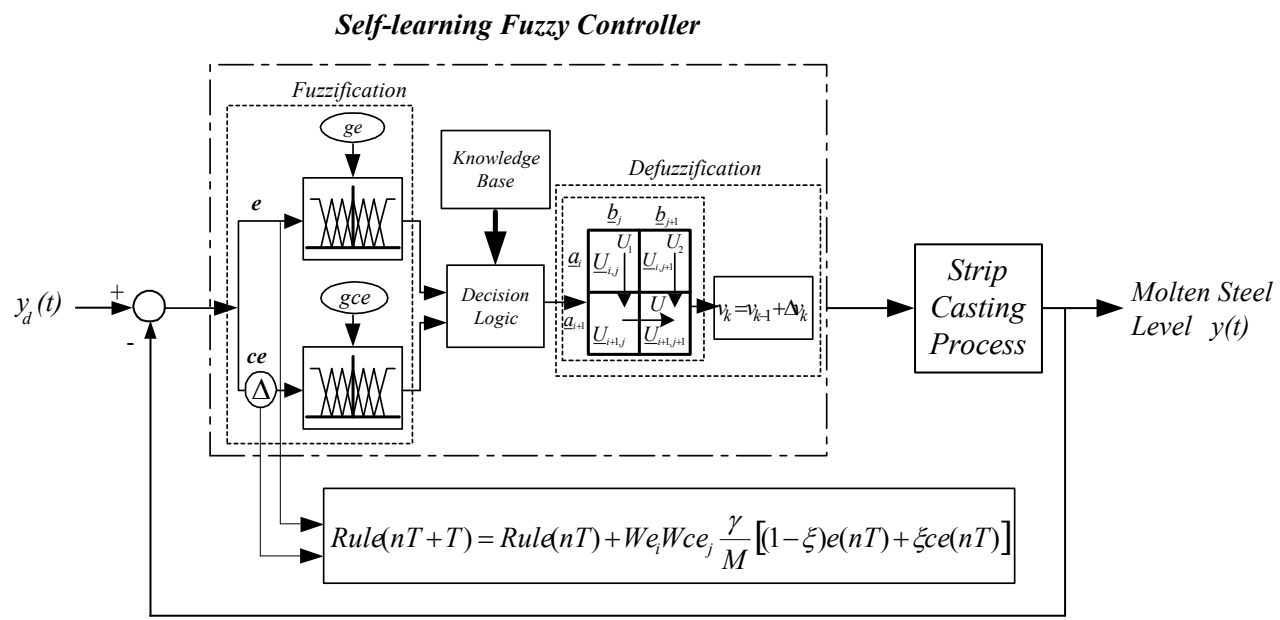

Fig. 2. The self-learning fuzzy control block diagram

The purpose of model estimation is to find the relationship between the system output performance and the control input. Based on the estimation model, the performance measure can be used to calculate the correction value of each fuzzy rule. However, it's difficult to establish an appropriate performance decision table for each control system. A real-time linguistic self-learning fuzzy control strategy with a modification equation is used instead of the performance decision table to eliminate this difficulty. During the rule modification period, the size of rule table is limited to that of the original fuzzy rule table, and the correction value of each fuzzy rule is introduced into the original fuzzy rules as a new control rule. This approach can both improve the database expansion shortcoming of the Procky scheme (Procky and Mamdani 1979) and increase the computing speed. In addition, the system output characteristic can be monitored by definite design parameters. An auto-regression and moving average (ARMA) model can be used to represent the system dynamic response feature: 


$$
\begin{gathered}
X(n T)=A\left(z^{-1}\right) X(n T-T)+M u(n T-m T)+B\left(z^{-1}\right) u(n T-m T-T) \\
A\left(z^{-1}\right)=a_{0}+a_{1} z^{-1}+\cdots+a_{r-1} z^{-(r-1)} \\
B\left(z^{-1}\right)=b_{0}+b_{1} z^{-1}+\cdots+b_{s-m-1} z^{-(s-m-1)}
\end{gathered}
$$

where $\mathrm{mT}$ is the time delay of the system and $\mathrm{M}$ is the system direct forward gain of the control system. The values of $\mathrm{r}, \mathrm{s}$ and $\mathrm{m}$ depend on the dynamic characteristics of the control system. They are difficult to estimate for the given system due to the non-linearity and uncertainty. Fortunately, fuzzy control has model-free feature and it does not require a definite mathematical model and system parameters. If the system is excited with a different control input $\mathrm{u}^{\prime}(\mathrm{nT}-\mathrm{mT})$ at time step $\mathrm{nT}-\mathrm{mT}$, there will be a new output value $\mathrm{X}^{\prime}(\mathrm{nT})$ at time step nT . Substituting $\mathrm{u}^{\prime}(\mathrm{nT}-\mathrm{mT})$ into Equation (9) will generate:

$$
X^{\prime}(n T)=A\left(z^{-1}\right) X(n T-T)+M^{\prime}(n T-m T)+B\left(z^{-1}\right) u(n T-m T-T)
$$

Then, the output difference between Equation (9) and (10) can be obtained:

$$
\begin{gathered}
\Delta X \equiv X^{\prime}(n T)-X(n T) \\
\Delta u \equiv u^{\prime}(n T-m T)-u(n T-m T)
\end{gathered}
$$

The relationship between control input difference and corresponding output deviations are established.

$$
\begin{gathered}
X^{\prime}(n T)-X(n T)=M\left[u^{\prime}(n T-m T)-u(n T-m T)\right] \\
\Delta X=M \Delta u \quad \text { or } \quad \frac{\Delta X}{\Delta u}=M
\end{gathered}
$$

If a system at time step nT has an output error $\Delta \mathrm{X}$ and an error change $\Delta \dot{\mathrm{X}}$ needed be compensated, the theoretical correction values of the corresponding control input are $\Delta \mathrm{u}_{\mathrm{e}}$ and $\Delta \mathrm{u}_{\mathrm{ce}}$, respectively. Then

$$
\Delta \mathrm{u}_{\mathrm{e}}=\frac{\Delta \mathrm{X}}{\mathrm{M}} \quad \text { and } \quad \Delta \mathrm{u}_{\mathrm{ce}}=\frac{\mathrm{T} \Delta \dot{\mathrm{X}}}{\mathrm{M}}
$$

Since the system has one control input $u$ only, the above two terms must be combined together appropriately into the control input correction. Generally, the following equation can be chosen:

$$
\Delta \mathrm{u}=(1-\xi) \Delta \mathrm{u}_{\mathrm{e}}+\xi \Delta \mathrm{u}_{\mathrm{ce}}, \quad 0 \leq \xi<1
$$

where $\xi$ is a design parameter representing the weighting distribution between $\Delta \mathrm{u}_{\mathrm{e}}$ and $\Delta \mathrm{u}_{\mathrm{ce}}$. If there is a large deviation between the system output $\mathrm{X}(\mathrm{nT})$ and the desired value $X_{d}$, the suitable $X^{\prime}(n T)$ value is chosen between $X(n T)$ and $X_{d}$ with a weighting parameter $\gamma$. Then the system output response $X$ can approach $X_{d}$ gradually. 


$$
\mathrm{X}^{\prime}(\mathrm{nT})=(1-\gamma) \mathrm{X}(\mathrm{nT})+\gamma \mathrm{X}_{\mathrm{d}}, \quad 0<\gamma<1
$$

Then the output and output change rate deviations become

$$
\begin{gathered}
\Delta \mathrm{X}(\mathrm{nT})=\gamma\left[\mathrm{X}_{\mathrm{d}}-\mathrm{X}(\mathrm{nT})\right]=\gamma \mathrm{e}(\mathrm{nT}) \\
\Delta \dot{\mathrm{X}}(\mathrm{nT})=\gamma \dot{\mathrm{e}}(\mathrm{nT})=\frac{\gamma}{\mathrm{T}} \mathrm{ce}(\mathrm{nT})
\end{gathered}
$$

From Equations (13) and (17), the correction value of the control input can be represented as:

$$
\Delta \mathrm{u}=\frac{\gamma}{\mathrm{M}}[(1-\xi) \mathrm{e}(\mathrm{nT})+\xi \mathrm{ce}(\mathrm{nT})]
$$

In this study, the output error $\mathrm{E}$ and the change of error $\mathrm{CE}$ are normalized and divided into eleven equal span fuzzy subsets within $[-1,+1]$. The fuzzy input variables, i.e. the system output error and the change of error will stimulate two fuzzy subsets of the E and CE universe of discourse, respectively for each control step. Since the control input $u$ is derived from the inference of fuzzy rules, four fuzzy rules will be influenced by the rule modification for each control step. The correction value of each fuzzy rule is proportional to its excitation strength $\mathrm{w}$, which is designed as a triangular membership function and calculated with a linear interpolation algorithm. Then the control input correction equation of the $i$ th rule is:

$$
\begin{aligned}
\mathrm{u}_{\mathrm{i}}(\mathrm{nT}+\mathrm{T}) & =\mathrm{u}_{\mathrm{i}}(\mathrm{nT})+\Delta \mathrm{u}_{\mathrm{i}} \\
& =\mathrm{u}_{\mathrm{i}}(\mathrm{nT})+\mathrm{w}_{\mathrm{ei}} \mathrm{w}_{\text {cei }} \frac{\gamma}{\mathrm{M}} \times[(1-\xi) \mathrm{e}(\mathrm{nT})+\xi \mathrm{ce}(\mathrm{nT})]
\end{aligned}
$$

The term $\gamma / \mathrm{M}$ in the above equation can be considered as a designing learning factor. Besides this intelligent has a rule modification equation as the above equation, its operating processes are the same as the fuzzy logic controller. The general form of a self-learning fuzzy control rule can be expressed as:

$$
\text { Rule }_{\mathrm{i}} \text { : IF } \Delta \mathrm{X} \text { is } A \text { AND } \Delta \dot{\mathrm{X}} \text { is } B \text {, THEN } U \text { is } C
$$

where Rule $_{i}$ is the $i$ th rule, $\Delta \mathrm{X}$ and $\Delta \dot{\mathrm{X}}$ are the states of the system output to be controlled, $U$ is the control input and $A, B$ and $C$ are the corresponding fuzzy subsets of the input and output universe of discourse, respectively. The output importance of each rule is dependent on the membership functions of the linguistic input and output variables. An equal-span triangular membership function shown in Fig. 3 is employed in this article for fuzzifying the input and output variables. The membership function used in the present article for fuzzification is of a triangular type. The function can be expressed as:

$$
\mu(\mathrm{x})=\frac{1}{\mathrm{~W}}(-|\mathrm{x}-\delta|+\mathrm{W})
$$

where $\mathrm{W}$ is the distribution span of the membership function, $\mathrm{x}$ is the fuzzy input variable and $\delta$ is the parameter defining the value 1 of the membership function. The height method 
is employed to defuzzify the fuzzy variable in order to obtain the control input for each control step. The equation can be described as:

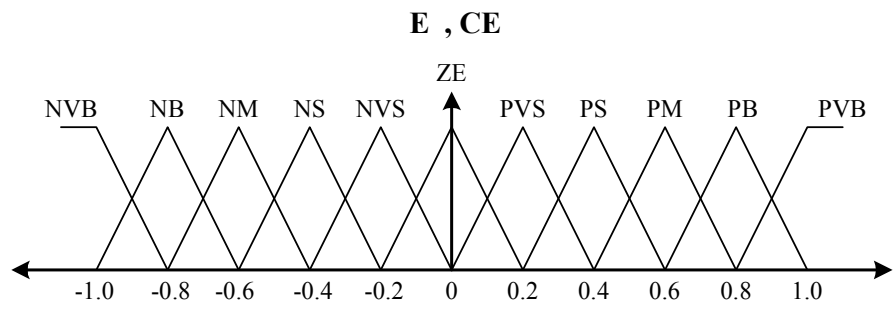

(a)

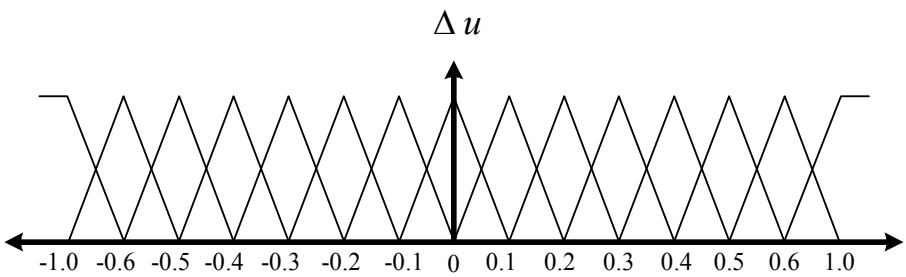

(b)

Fig. 3. The fuzzy membership functions for (a) the inputs control variables errors; (b) the control input

$$
\mathrm{y}^{0}=\frac{\sum \mathrm{w}_{\mathrm{i}} \mathrm{y}_{\mathrm{i}}}{\sum \mathrm{w}_{\mathrm{i}}}, \quad \mathrm{w}_{\mathrm{i}}=\prod_{\mathrm{j}} \mu_{\mathrm{A}_{\mathrm{ij}}}\left(\mathrm{x}_{\mathrm{j}}^{0}\right)
$$

where $\mu_{\mathrm{A}_{\mathrm{ij}}}\left(\mathrm{x}_{\mathrm{j}}^{0}\right)$ is the linguistic value of the fuzzy set variable, $\mathrm{w}_{\mathrm{i}}$ is the weight of the corresponding rules that have been activated, $y_{i}$ is the resulting fuzzy control value of the ith fuzzy rule and $y^{0}$ is the net fuzzy control action. The two dimensional linear interpolation algorithm also can be used to calculate the inference of four fired fuzzy rules for obtaining the control value of each control step.

\section{Numerical results}

In order to verify the effectiveness of this intelligent controller, the following numerical simulations are performed in this study. The system parameters used in the simulation study are selected as: $R=650(\mathrm{~mm}), L_{r}=1350(\mathrm{~mm})$. These values are chosen from the previous researches (Joo et al. 2002, Park and Cho 2005). The variation of the input flow rate, $a(t)$, to describe the slow nozzle clogging and sudden unclogging is shown in Fig. 4 from reference (Joo et al. 2002). The input flow rate is dependent upon the viscosity of the molten steel, the molten steel level in the tundish, clogging and unclogging. The initial molten steel level and desired molten steel level were set to be 200 and $250 \mathrm{~mm}$, respectively. The sampling frequency was selected as $100 \mathrm{~Hz}$. The fuzzy control parameters ge and gce are chosen as 35 and 150. The weighting parameter $\xi$ and the learning factor $\gamma / \mathrm{M}$ in Equation 
(20) were chosen as 0.5 and 1/1.9, respectively. An equal-span triangular membership function shown in Fig. 3 is employed for fuzzifying the input and output variables.

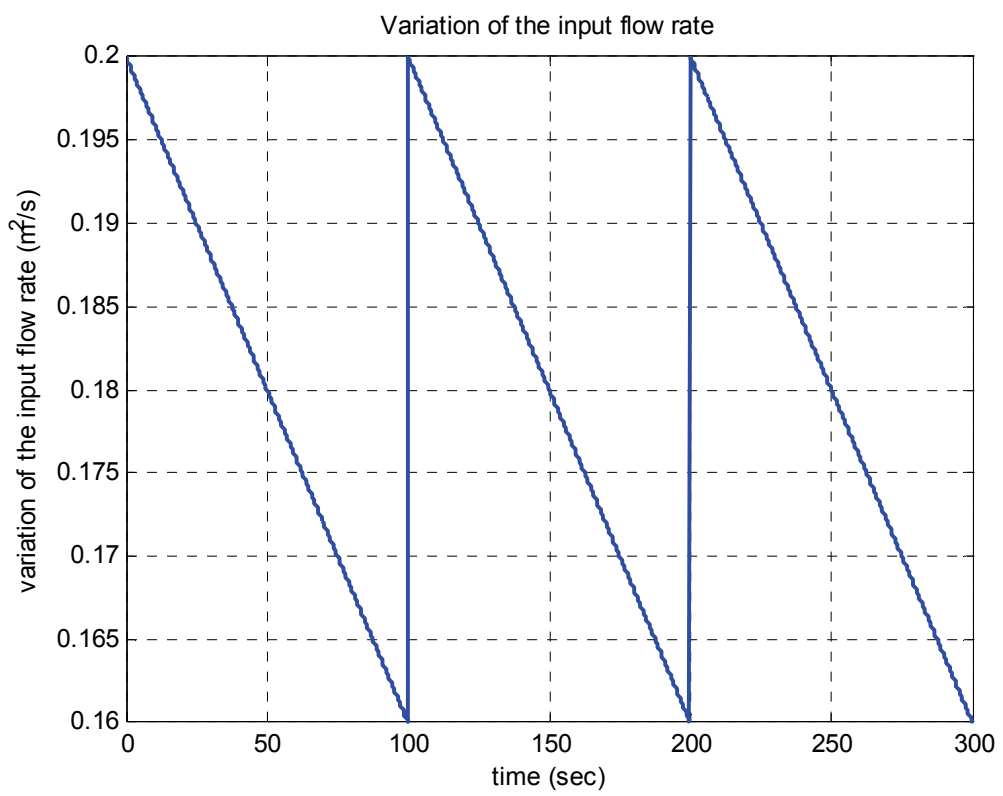

Fig. 4. Variation of the input flow rate

Case A: The parameters $\mathrm{x}_{\mathrm{g}}$ and $\mathrm{v}_{\mathrm{r}}$ are constants:

The system parameters roll gap $\mathrm{x}_{\mathrm{g}}$ and roll speed $\mathrm{v}_{\mathrm{r}}$ used in this simulation are set as constants, $v_{\mathrm{r}}=13(\mathrm{mpm})$ and $\mathrm{x}_{\mathrm{g}}=2(\mathrm{~mm})$. In practice, they are important to reach the desired molten steel level $y_{d}$ in short period of time without overshooting, and to guarantee the molten steel level within a bounded endurable region during the casting process. The dynamic responses of the controller based on numerical results are shown in Fig. 5 (transient response) and Fig. 6 (steady-state response). The variations of orifice opening is shown in Fig. 7. The dynamic responses and the variations of orifice opening of the traditional PID controller $\left(k_{p}=25, k_{i}=0.15, k_{d}=1\right)$ is shown in Figs. 8 and 9, respectively. Since the variation of the input flow rate has a sudden change from 0.16 to 0.2 $\mathrm{m}^{2} / \mathrm{s}$ at the moment of 100, 200 and $300 \mathrm{sec}$. The small change in times 100 and $200 \mathrm{sec}$ in Fig. 6 is due to the sudden variation of the input flow. It takes about 10 steps $(0.1 \mathrm{sec})$ for the height of molten steel, $\mathrm{y}$, converges to the desired molten steel level, $\mathrm{y}_{\mathrm{d}}$ by using this intelligent controller. The converging time of the molten steel level is faster than the result, $0.15 \mathrm{sec}$ of the PID controller. It can be observed that the steady-state error can be kept within $0.02 \mathrm{~mm}$ to the end of the control process even at the instants with the input flow rate variations due to the sudden unclogging shown in Fig. 4 . The steady-state error is smaller than the result, $0.5 \mathrm{~mm}$ of the PID controller. 
Case B: The parameters $\mathrm{x}_{\mathrm{g}}$ and $\mathrm{v}_{\mathrm{r}}$ are not constants:

Since the system roll gap $x_{g}$ and roll speed $v_{r}$ parameters may have some perturbations in the real strip casting process, the values of $x_{g}$ and $v_{r}$ with certain variation instead of constants are chosen in this simulation. These parameter perturbations are set as random variations with the maximum amplitude of $25 \%$ system nominal parameter values. The disturbances are added for the entire control process to represent the parameter perturbations. The dynamic responses of this intelligent controller based on numerical results are shown in Fig. 10 (transient response) and Fig. 11 (steady-state response). The variations of orifice opening is shown in Fig. 12. The dynamic responses and the variations of orifice opening of the traditional PID controller $\left(k_{p}=25, k_{i}=0.15, k_{d}=1\right)$ is shown in Figs. 13 and 14, respectively. It takes about 10 steps $(0.1 \mathrm{sec})$ for the height of molten steel, $\mathrm{y}$, to converge to the desired molten steel level, $\mathrm{y}_{\mathrm{d}}$, with $\pm 0.3 \mathrm{~mm}$ steady-state error by using this intelligent controller. The converging time of the molten steel level is faster than the result, $015 \mathrm{sec}$ of the PID controller and the steady-state error is smaller than the result, $\pm 1 \mathrm{~mm}$ of the PID controller even at the instants with the input flow rate variations due to the sudden unclogging.

Based on the simulation results, it can be observed that the self-learning fuzzy controller can regulate the molten steel level at the preset desired level without overshooting effectively.

(a) Molten steel level

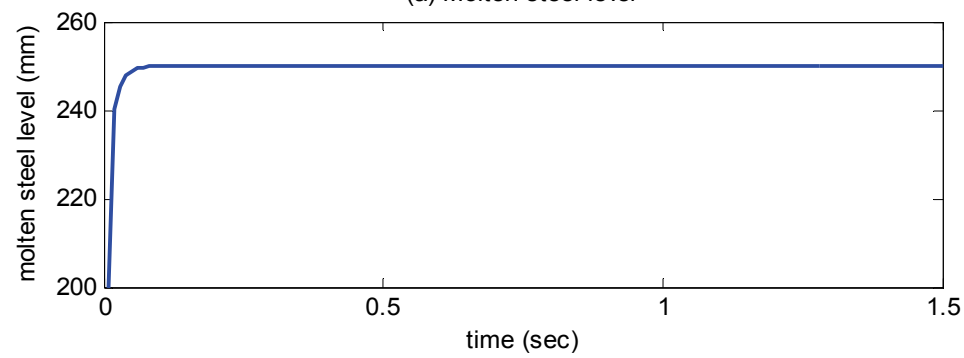

(b) Enlarged view of molten steel level

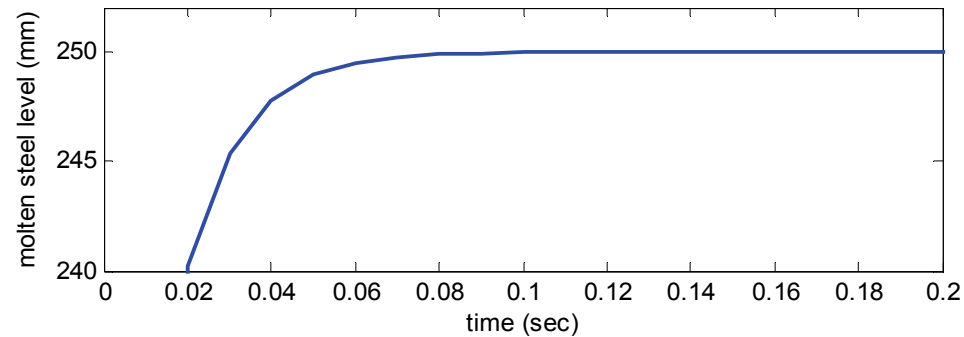

Fig. 5. Case A: Molten steel level (transient response) 
(a) Molten steel level

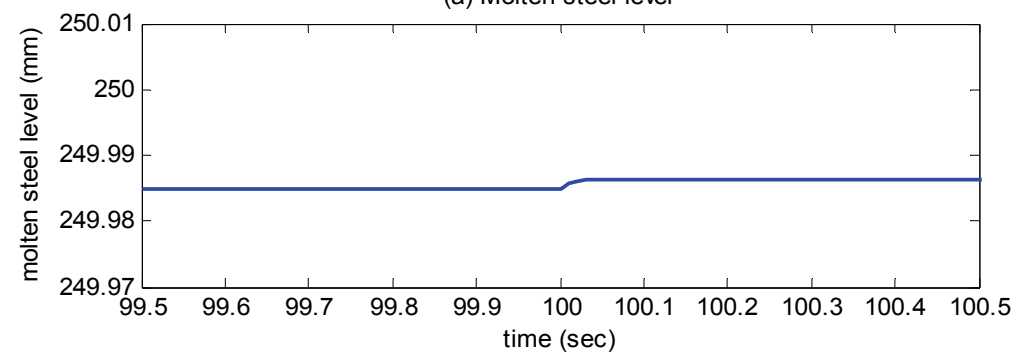

(b) Molten steel level

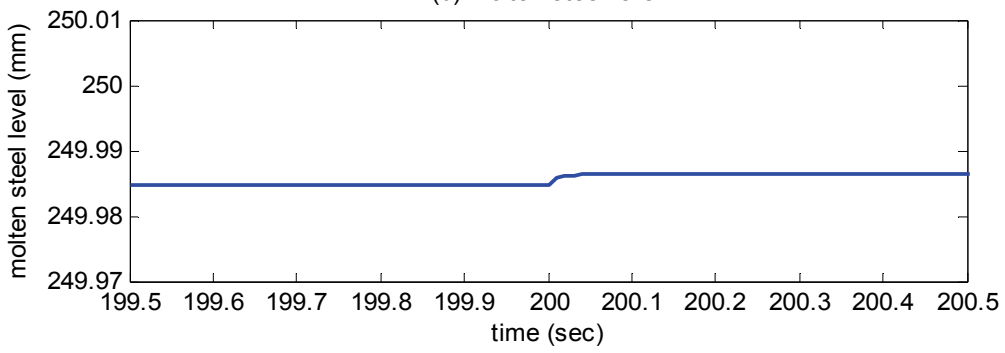

Fig. 6. Case A: Molten steel level (steady-state response)

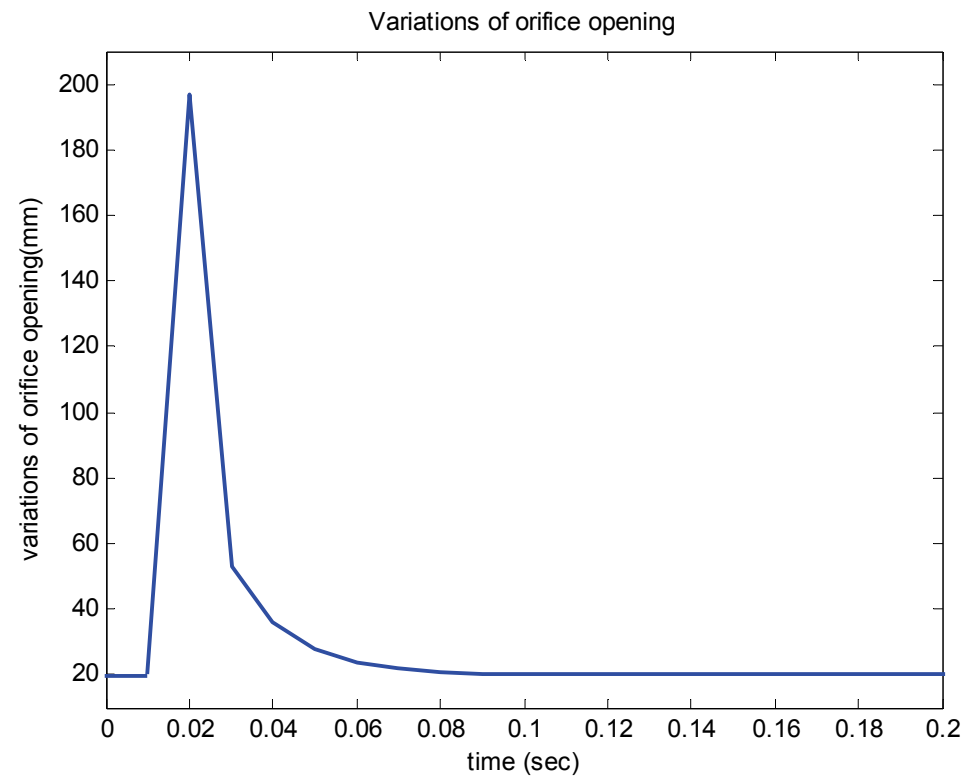

Fig. 7. Case A: Variations of orifice opening 
(a) Molten steel level

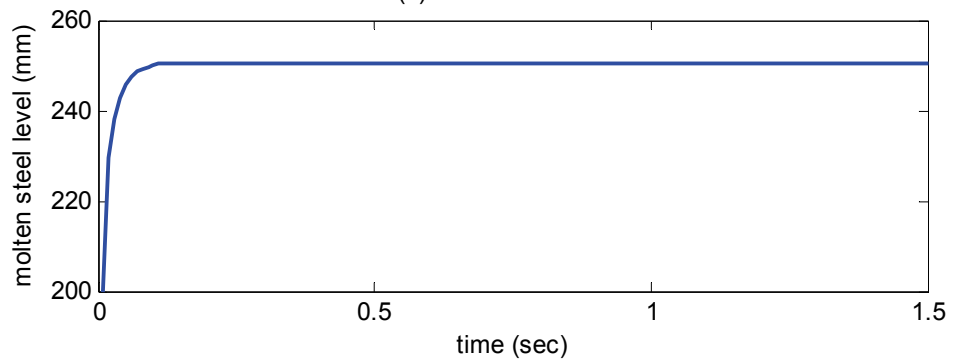

(b) Enlarged view of molten steel level

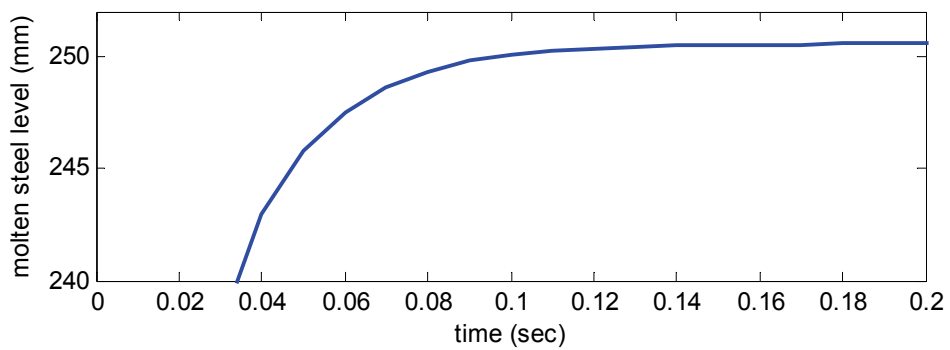

Fig. 8. Case A: Molten steel level (PID controller: $\mathrm{k}_{\mathrm{p}}=25, \mathrm{k}_{\mathrm{i}}=0.15, \mathrm{k}_{\mathrm{d}}=1$ )

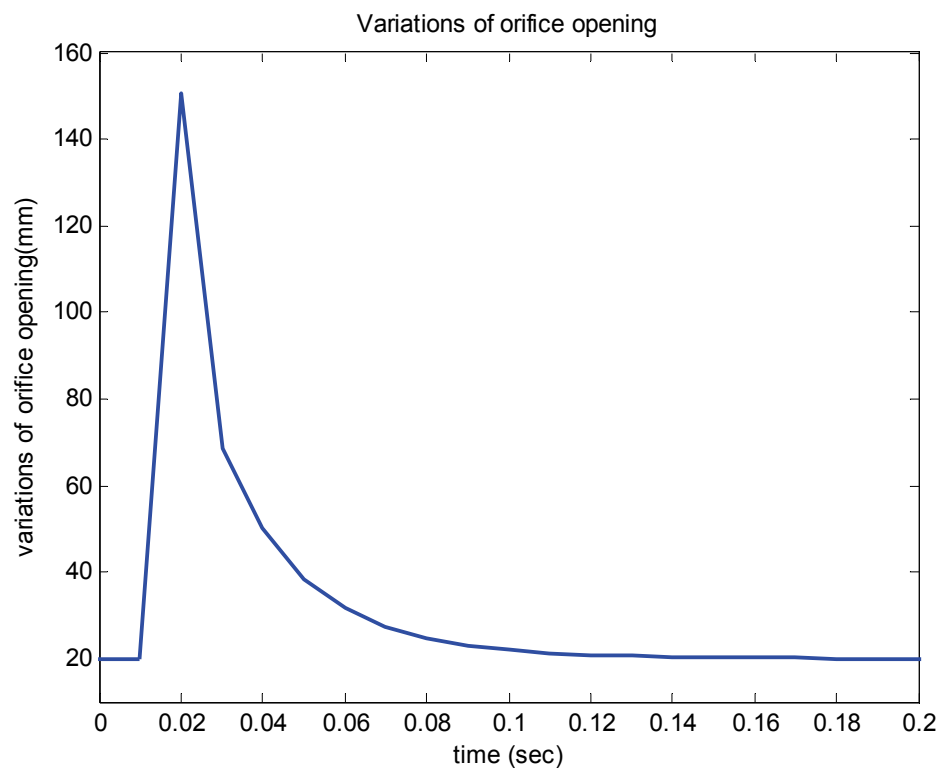

Fig. 9. Case A: Variations of orifice opening (PID controller: $k_{p}=25, k_{i}=0.15, k_{d}=1$ ) 
(a) Molten steel level

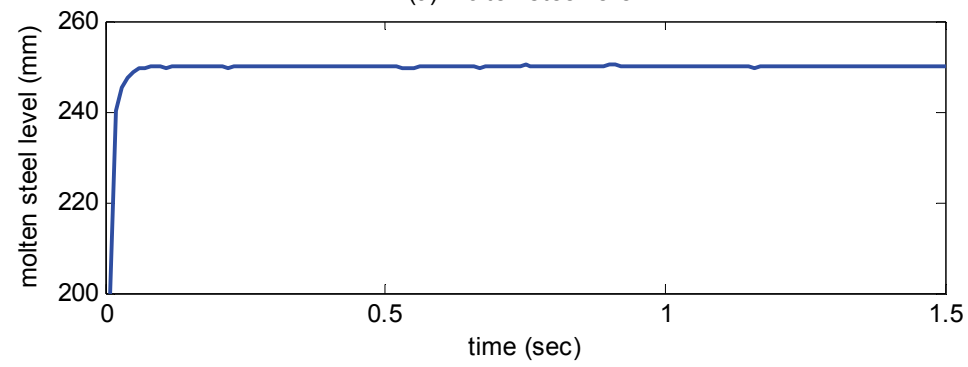

(b) Enlarged view of molten steel level

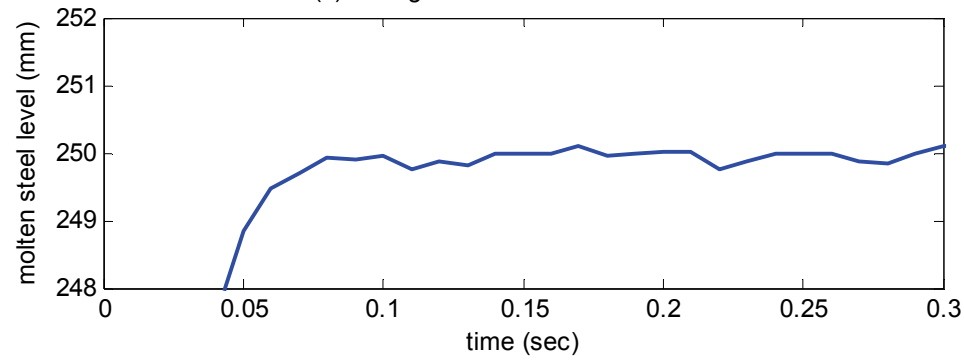

Fig. 10. Case B: Molten steel level (transient response)

(a) Molten steel level

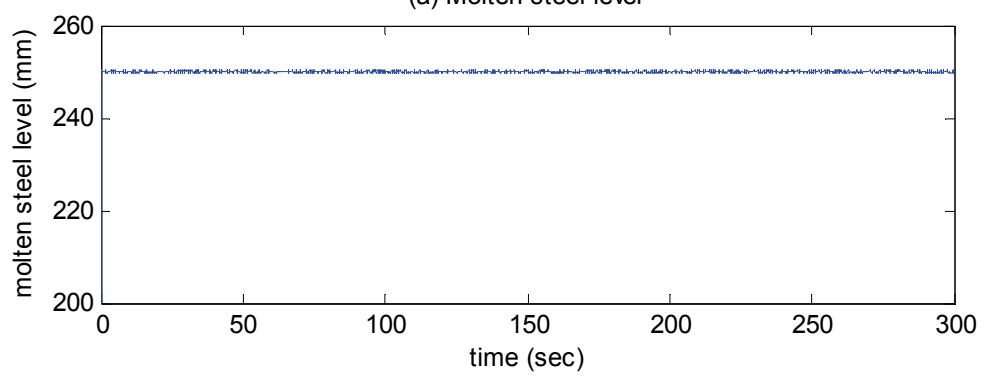

(b) Enlarged view of molten steel level

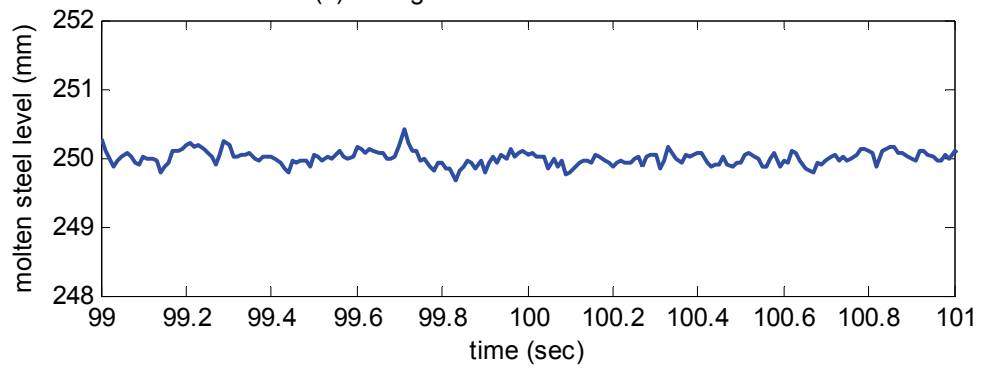

Fig. 11. Case B: Molten steel level (steady-state response) 


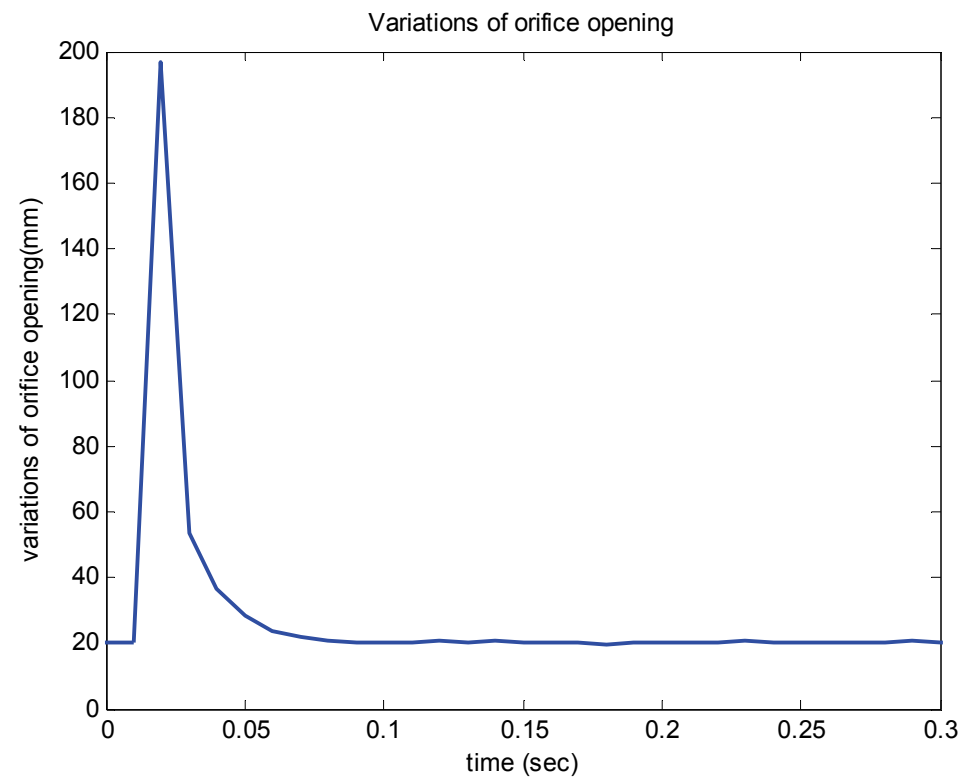

Fig. 12. Case B: Variations of orifice opening

(a) Molten steel level

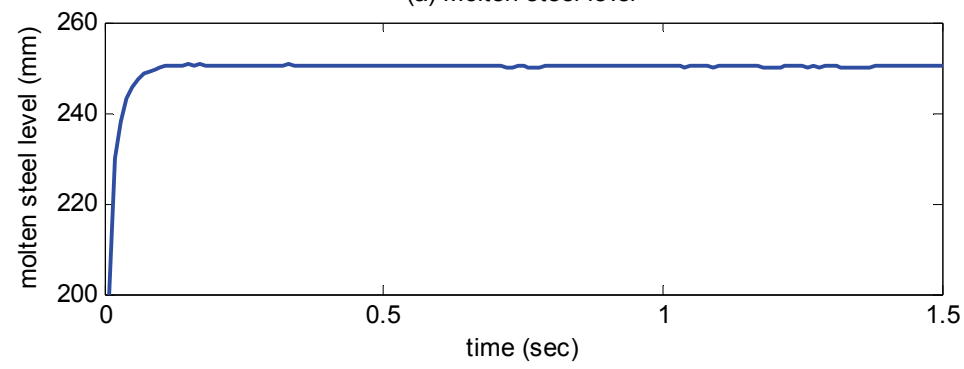

(b) Enlarged view of molten steel level

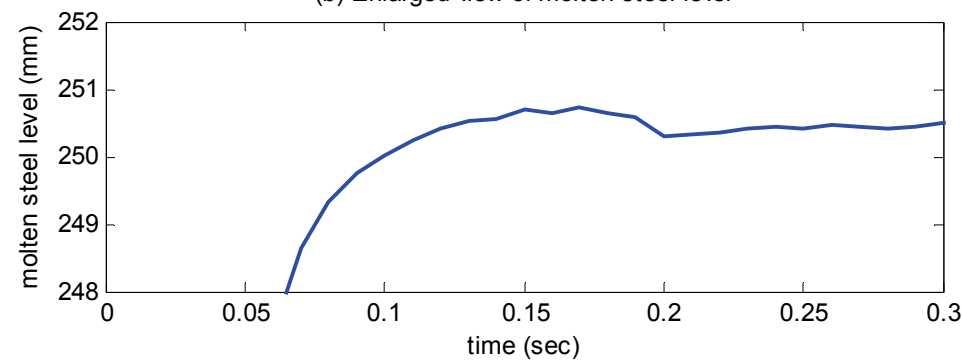

Fig. 13. Case B: Molten steel level (PID controller: $k_{p}=25, k_{i}=0.15, k_{d}=1$ ) 


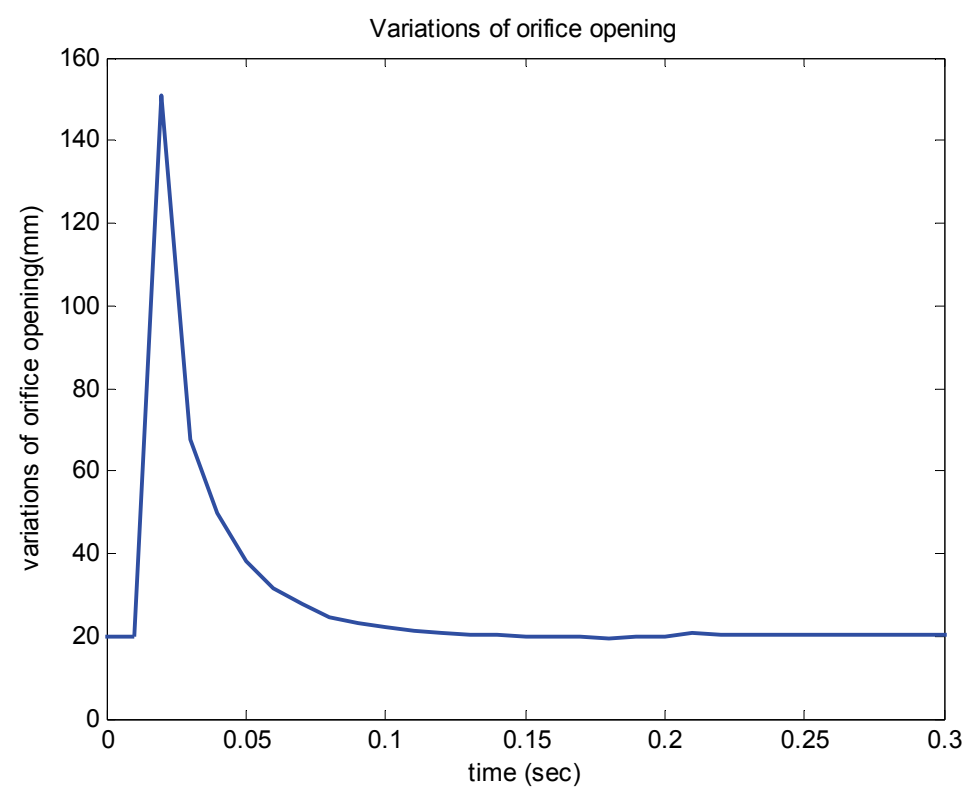

Fig. 14. Case B: Variations of orifice opening (PID controller: $\mathrm{k}_{\mathrm{p}}=25, \mathrm{k}_{\mathrm{i}}=0.15, \mathrm{k}_{\mathrm{d}}=1$ )

\section{Conclusion}

The twin-roll strip casting process dynamics has the properties of nonlinear uncertainty and time-varying characteristics. It is difficult to establish an accurate process model for designing a model-based controller to monitor the strip quality. A model-free self-learning fuzzy controller is employed to control the molten steel level of the strip casting process. This intelligent control strategy has online learning ability for responding to the system's nonlinear and time-varying behaviors during the molten steel level control. From the simulation results, it can be observed that the converging time of the molten steel level is less than $0.1 \mathrm{sec}$ and the steady-state error is less than $0.3 \mathrm{~mm}$ for both simulation cases. In addition, this control strategy can monitor the molten steel at the preset desired level without overshooting effectively to guarantee the steel strip casting quality. Furthermore, from the control results, it can be concluded that the performance of this self-learning fuzzy controller is better than that of a traditional PID controller. This has reduced significantly the trial-and-error efforts of implementing a PID control strategies.

\section{References}

Chen, H.Y. \& Huang, S.J. (2004). Ti6Al4V laser alloying process control by using a selforganizing fuzzy controller. International Journal of Machine Tools \& Manufacture, Vol. 44, pp. 1653-1665. 
Cook, R., Grocock, P.G., Thomas, P.M., Edmonds, D.V. \& Hunt, J.D. (1995). Development of the twin-roll casting process. Journal of Materials Processing Technology, Vol. 55, pp. 76-84.

Dussud, M., Galichet, S. \& Foulloy, L.P. (1998). Application of fuzzy logic control for continuous casting mold level control. IEEE Transactions on Control System Technology, Vol. 6, pp. 246-256.

Graebe, S.F., Goodwin, G.C. \& Elsley, G. (1995). Control design and implementation in continuous steel casting. IEEE Control Systems Magazine, Vol. 15, pp. 64-71.

Hesketh, T., Clements, D.J. \& Williams, R. (1993). Adaptive mould level control for continuous steel slab casting. Automatica, Vol. 29, pp. 851-864.

Hong, K.S., Kim, J.G. \& Tomizuka, M. (2001). Control of strip casting process: decentralization and optimal roll force control. Control Engineering Practice, Vol. 9, pp. 933-945.

Joo, M.G., Kim, Y.H. \& Kang, T. (2002). Stable adaptive fuzzy control of the molten steel level in the strip casting process. IEE Proceedings on Control Theory Applications, Vol. 149, pp. 357-364.

Liang, X., Pan, F., Zhou, S., Ding, P. \& Xu, X. (1997). Edge containment of a twin-roll caster for near-net-shape strip casting. Journal of Materials Processing Technology, Vol. 63, pp. 788-791.

Park, Y. \& Cho, H. (2005). A fuzzy logic controller for the molten steel level control of strip casting process. Control Engineering Practice, Vol. 13, pp. 821-834.

Procky, T.J. \& Mamdani, E.H. (1979). A linguistic self-organizing process controller. Automatica, Vol. 15, pp. 15-30. 


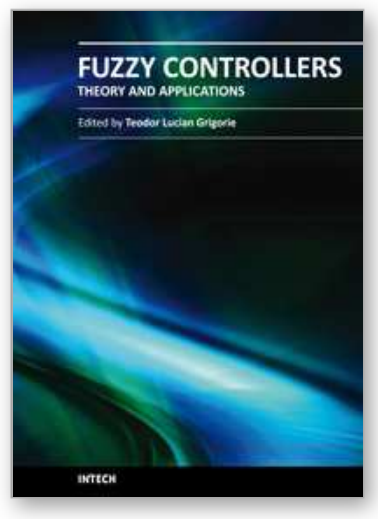

\author{
Fuzzy Controllers, Theory and Applications \\ Edited by Dr. Lucian Grigorie
}

ISBN 978-953-307-543-3

Hard cover, 368 pages

Publisher InTech

Published online 28, February, 2011

Published in print edition February, 2011

Trying to meet the requirements in the field, present book treats different fuzzy control architectures both in terms of the theoretical design and in terms of comparative validation studies in various applications, numerically simulated or experimentally developed. Through the subject matter and through the inter and multidisciplinary content, this book is addressed mainly to the researchers, doctoral students and students interested in developing new applications of intelligent control, but also to the people who want to become familiar with the control concepts based on fuzzy techniques. Bibliographic resources used to perform the work includes books and articles of present interest in the field, published in prestigious journals and publishing houses, and websites dedicated to various applications of fuzzy control. Its structure and the presented studies include the book in the category of those who make a direct connection between theoretical developments and practical applications, thereby constituting a real support for the specialists in artificial intelligence, modelling and control fields.

\title{
How to reference
}

In order to correctly reference this scholarly work, feel free to copy and paste the following:

Hung-Yi Chen and Shiuh-Jer Huang (2011). Molten Steel Level Control of Strip Casting Process Monitoring by Using Self-Learning Fuzzy Controller, Fuzzy Controllers, Theory and Applications, Dr. Lucian Grigorie (Ed.), ISBN: 978-953-307-543-3, InTech, Available from: http://www.intechopen.com/books/fuzzy-controllers-theoryand-applications/molten-steel-level-control-of-strip-casting-process-monitoring-by-using-self-learning-fuzzycontroll

\section{INTECH}

open science | open minds

\section{InTech Europe}

University Campus STeP Ri

Slavka Krautzeka 83/A

51000 Rijeka, Croatia

Phone: +385 (51) 770447

Fax: +385 (51) 686166

www.intechopen.com

\section{InTech China}

Unit 405, Office Block, Hotel Equatorial Shanghai

No.65, Yan An Road (West), Shanghai, 200040, China 中国上海市延安西路65号上海国际贵都大饭店办公楼405单元

Phone: $+86-21-62489820$

Fax: +86-21-62489821 
(C) 2011 The Author(s). Licensee IntechOpen. This chapter is distributed under the terms of the Creative Commons Attribution-NonCommercialShareAlike-3.0 License, which permits use, distribution and reproduction for non-commercial purposes, provided the original is properly cited and derivative works building on this content are distributed under the same license. 